\title{
Efficiency of Calatonia on clinical parameters in the immediate post-surgery period: a clinical study
}

\author{
Elaine Ferreira Lasaponari ${ }^{1}$ \\ Aparecida de Cássia Giani Peniche ${ }^{2}$ \\ Ruth Natalia Teresa Turrini \\ Eliane da Silva Grazziano ${ }^{3}$
}

Objective: to assess the efficiency of the Calatonia technique about clinical parameters and pain in the immediate post-surgical phase. Method: a randomised study was carried out with 116 patients subjected to a cholecystectomy, by laparoscopy, divided into an experimental group (58 patients) and a placebo group (58 patients). The experimental group received the Calatonia technique, while the placebo was only subjected to non-intentional touches. Results: The placebo group and the experimental group were considered homogeneous in terms of the variables: sex, age, physical status classification, duration of surgical procedures and also the time spent recovering in the Post-Anaesthetic Recovery Room. The only variable to show a statistically significant difference was the axillary temperature of the body. In relation to pain, the experimental group showed significant results, and hence it is possible to deduce that the relaxation caused by the Calatonia technique brought some relief of the general situation of pain. Conclusion: The application of Calatonia can take up the function of a resource complementary to assistance in the period immediately after surgery. Brazilian Register of Clinical Trials, UTN U1111-1129-9629.

Descriptors: Anesthesia Recovery Period; Therapeutic Touch; Complementary Therapies; Relaxation Therapy.

\footnotetext{
${ }_{1}^{1}$ MSc, RN, Hospital Alemão Oswaldo Cruz, São Paulo, SP, Brazil.

${ }^{2} \mathrm{PhD}$, Associate Professor, Escola de Enfermagem, Universidade de São Paulo, São Paulo, SP, Brazil.

${ }^{3} \mathrm{PhD}$, Professor, Departamento de Enfermagem, Universidade Federal de São Carlos, São Carlos, SP, Brazil.
}

\footnotetext{
Corresponding Author:

Elaine Ferreira Lasaponari

Hospital Alemão Oswaldo Cruz

Rua João Julião, 331

Bairro: Bela Vista

CEP: 01323-903, São Paulo, SP, Brasil

E-mail: elainelasaponari@ig.com.br
} 


\section{Introduction}

The post-anaesthetic recovery period is defined as critical, and is located between the moment when the administration of anaesthetic drugs is stopped and the moment when the basic conditions of the patient return. It is also characterised by organic instabilities which result from anaesthetic and surgical trauma, such as, for example, haemodynamic, respiratory, gastrointestinal and consciousness changes, also associated to the presence of pain and hypothermia, which requires constant surveillance by the medical and nursing teams followed by an identification of the problem and intervention for the treatment thereof ${ }^{(1)}$.

The nurse must have sufficient knowledge and skill to provide anaesthetic and surgical assistance to the clients subjected to different kinds of surgery, be they dependent on respirators or not. Apart from the technical skills which are required of nurses around the clock, there is also a need for training and supervision of the components of the nurse's team ${ }^{(2)}$.

In the light of the identification of risk factors, it shall be up to the nurse to carry out an overall appraisal of the patient, and also of the patient's respiratory and cardiovascular functions, central nervous system, reported or subjective pain, temperature, motor activities, hydroelectronic balance, infusions, drainage, perfusion, bleeding, conditions of bandage, and occurrence of nausea or vomiting(3).

The nurse may, at this moment, make use of complementary health techniques for the relief of any post-surgical changes that have been detected, these techniques including Calatonia, for example.

We understand alternative and complementary therapies (AT/CT) as a wide domain including resources for cure, that includes all health systems, modes and practices, and also accompanying theories and beliefs; it also includes all practices and ideas as self-defined by their users as preventing or treating illnesses or promoting health and well-being ${ }^{(4)}$.

In 1996, the Nursing Intervention Classification (NIC) was created, defining nursing intervention as being any treatment, based on clinical judgement of knowledge, that the nurse carries out to improve the patient's results. Nursing interventions include direct and indirect care; the treatment may be started by the nurse, doctor, or any other providing agent. Direct care intervention includes both physiological and psychological nursing actions. The treatment started by the nurse consists of an intervention in reply to the diagnosis made by the nursing team; an autonomous action based on scientific reasoning ${ }^{(5)}$.

Based on scientific and technical knowledge and also on international diagnostic nursing classifications of NANDA International (NANDA-I)(6) and NIC(5), by means of systematisation of nursing care, a joint force for the multiprofissional health team is thus achieved, so as to obtain a better prognosis and recovery of the patient.

As a nursing diagnosis, the NANDA-I system includes, as part of its classification, an item referring to Disorders of the Energy Field, with the item of assessment in this case being the therapeutic touch(5).

Complementary therapies offer a wide field of action, as the constant contact between nurse and patient favours the implementation of such therapies, in order to soothe pain, to promote integralised assistance that is systematised and standardised, and also to improve the patient's quality of life within a hospital environment.

Calatonia is a relaxation technique which acts at the cortical level and which, through cutaneous sensitivity, leads to interior harmony, as well as physical and psychological well-being. This technique is applied to certain parts of the feet, and can be used either as central treatment or as help within the psychotherapeutic $\operatorname{processes}^{(7)}$.

A study about the effects of Calatonia on the presurgery phase of surgical patients showed a reduction of anxiety and also a reduction of the clinical parameters that have been assessed, albeit not in a way that is statistically significant ${ }^{(8)}$.

In a post-anaesthetic recovery room, one can see different degrees of progress among the patients. Each patient has a different way of facing the situation, some show extreme restlessness or confusion, while others appear calm or even drowsy, even though they may be subjected to the same type of surgical and anaesthetic procedure. In the light of these particularities of the responses to anaesthetic and surgical trauma, the nursing interventions, apart from considering the antecedent pathologies, type of surgery and the anaesthetic applied, are aimed at the physiological changes caused by the anaesthetic and surgical act, such as changes in the level of conscience, the presence of pain, nausea and vomiting, hydration conditions, body temperature, urination capacity, appearance and quantity of urinary debit, inspection of drainage systems, bleeding and bandages $^{(9)}$.

The introduction of complementary practices as part of nursing intervention, particularly in the case of 
Calatonia, could provide an individualised and humanised form of nursing care, aimed at the particularities of the human being and its integrality, rather than just a form of care based on a direct relationship between physiological changes and nursing intervention.

Studies show that, after a due review of specialised literature in the Nursing area between 1980 and 2005, focusing on AT/CT, the most used in national scientific production have been identified as Therapeutical Touch and Phytotherapy ${ }^{(10)}$.

The relation between these therapies and nursing has attracted a growing interest within the health area, throughout the world. Some researchers have started to look into this topic, exploiting its social, cultural, economic and political context, as well as specific affinities between these therapies and the nursing profession (11-12). However, most of this work has been carried out in the United Kingdom, in Australia, in Canada and also in the United States.

After an analysis of several different texts, the authors point out that the integrative approach in alternative therapies shows an aspect of transformation of cultural values in contemporary societies. In their results, they mention a chart containing the alternative therapeutical practices as offered in the municipality of Rio de Janeiro, a chart on which we highlight the diversity present, including the use of Calatonia(13).

A resolution published by the Federal Nursing Council (Conselho Federal de Enfermagem - COFEN), number 197/97, through Normative Opinion No. 004/95, establishes and recognises the use of alternative therapies as a speciality and/or qualification of the Nursing professional, provided this professional has passed after taking a course duly certified by a teaching institution or similar entity, with a minimum courseload of 360 hours ${ }^{(14-15)}$

The action of Calatonia occurs through subtle skin touches, says Dr Sándor, the creator of the Calatonia technique. These stimuli as generated act upon the countless nerve receptors that exist at this location, and which shall be transmitted naturally along the neurological routes to which they are connected by the nervous system as a whole. Due to the lightness of its touch, the effects are more profound, thus providing regulation and tonification, slowly creating a balance between all systems: bone, circulatory, muscular, hormonal, digestive, renal, respiratory and lymphatic ${ }^{(7)}$.

The expression Catalonia shows a condition of muscular releasing and/or distention, but not only from the muscular point of view in the widest sense, also referring to those possibilities for the reorganisation of internal tensions(16).

It is therefore understood that in the pre-surgery and post-surgery periods, Calatonia could be used as a form of complementary and interdisciplinar treatment, providing general well-being, both psychological and physical, especially when considering that the patient submitted to anaesthetic-surgical treatment suffers physiological and emotional aggressions which lead to full destabilisation of the patient ${ }^{(8)}$.

Even though the neuroendocrine changes are necessary for the individual to survive, Calatonia is proposed in this study with the function of reducing, as much as possible, the physical trauma and psychological suffering that affects the patient, through physiopsycological reorganisation, that shall be responsible for physical and emotional well-being.

\section{Objectives}

The purpose of this project is to assess the efficiency of Calatonia with regard to clinical conditions (systematic arterial blood pressure, heart rate, breathing rate, axillary body temperature, oxygen saturation and presence of pain, in the period immediately following surgery.

\section{Casuistic and method}

The method used is that of a randomised and controlled clinical trial which compared the effects and the value of an intervention (Calatonia) in a random manner, in two groups (placebo and experimental groups). This study was carried out at a private tertiary general hospital, predominantly for surgery, in the central region of the municipality of São Paulo, with a surgery centre with 16 operating theatres and a unit for postanaesthetic recovery with 18 beds. The average volume of surgery is 1,100 surgical operations per month, while the Post-Anaesthetic Recovery Room (PARR) treats an average of 950 patients/month.

The estimated sample size for binomial proportions with test power of $80 \%$ has defined a sample size of 116 individuals, with 58 in each group (placebo and experimental), which are randomly distributed using a randomisation table(17).

The criteria for inclusion were: higid patients (ASA 1 ) and those with some associated comorbidity (ASA 2), according to the classification proposed by the American Society of Anaesthesiology (ASA), subjected to a procedure for cholecystectomy by videolaparoscopy under general anaesthesia; a period of at least 60 minutes in the PARR. 
For data collection, we used an instrument with two different components: (1) data related to the presurgery period, including hospital registration number, sex, age, date and time of the operation, vital signs (non-invasive arterial blood pressure, heart beat, breathing rate and axillary body temperature) and also the ASA classification; (2) data related to the immediate post-surgery phase, including anaesthetic and surgical procedures carried out, the duration of such procedures, time in the PARR, clinical parameters (non-invasive arterial blood pressure, heart beat, breathing rate, axillary body temperature and oxygen saturation) and also a numerical verbal assessment of pain.

\section{Collection procedure}

The collection of data started during the pre-surgery visit, where the patients were invited to participate in the study, and those who agreed were then given an explanation of the aims and purposes of the study and also received the informed consent form (ICF). At this moment, the patient's medical records were checked and then personal data, clinical parameters and classification of the physical state (ASA) were also noted down.

The immediate post-operative phase was carried out while the patient was at the RPA unit. After the patient was admitted to the RPA, there was the collection of data about the following clinical parameters on admission $\left(t_{0}\right)$ : systematic arterial blood pressure, heartbeat, breathing frequency, axillary body temperature, oxygen saturation, assessment of pain. It must be stressed also that these clinical parameters were assessed throughout the period of permanence at the SPRA, or, in other words, every 15 minutes for a period of one hour. Straight afterwards, there was the application of the Calatonia technique on the patients of the experimental group.

In relation to the placebo group, this same monitoring sequence was followed but without the Calatonia intervention, just with touches. This meant that the toes were touched without any therapeutical intention and in sequential manner, in their anatomical presentation, which is different from the original sequence for application of the Calatonia technique.

The application of Calatonia was made on admittance $\left(t_{0}\right)$ and again after 60 minutes at the SPRA $\left(t_{1}\right)$. The estimated time for each application of the Calatonia technique was 20 minutes, with two minutes for each area as determined, thus closing the session. The basic procedure of the Calatonia technique is a sequence of nine touches (Figure 1) which the professional carries out on the feet, on each toe, in two different points of the soles of the feet, heels and ankles, and also one more touch at the start of the calf, and could also have the addition of a tenth touch often known as the Calatonia of the Head, which is applied to the occipital region.

\begin{tabular}{|l|l|}
\hline \multicolumn{1}{|c|}{ Location of touch } & \multicolumn{1}{c|}{ Execution of the touch by the nurse } \\
\hline 1 - Third Toe & Touch with the middle finger above, and the thumb in the pulp of the third toe. \\
\hline 2 - Second Toe & Touch with index finger and thumb. \\
\hline 3 - Fourth Toe & Touch with ring finger and thumb. \\
\hline 4 - Baby Toe & Touch with little finger and thumb. \\
\hline 5 - Hallux & $\begin{array}{l}\text { Touch with all fingers, with the thumb on the underside; index and little fingers on the sides; and the ring } \\
\text { and middle fingers at the top, on the base of the nail. }\end{array}$ \\
\hline $6-1^{\text {st }}$ Point (sole of the feet - longitudinal arc) & Touch with index, ring and middle fingers, all together. \\
\hline 7 - $2^{\text {nd }}$ Point (concavity of longitudinal arc) & Touch in the same way as item 6. \\
\hline $8-$ Heel & $\begin{array}{l}\text { Lightly supported by the hands, whose fingers touch just below the medial malleoli, on one side, and } \\
\text { the thumbs enwrap around the lateral malleoli on the other. }\end{array}$ \\
\hline 9 - Calf & $\begin{array}{l}\text { With the heel supported by the forearm, tough the point with the index finger, middle finger and ring } \\
\text { finger, all together. }\end{array}$ \\
\hline 10 - Nape & $\begin{array}{l}\text { Touch the base of the occipital bone with the middle and ring ringers, and then the professional shall } \\
\text { slowly remove his or her hands, thereby closing the session. }\end{array}$ \\
\hline
\end{tabular}

Source: Assembled based on data obtained from FARAH, RM - Body work and the psychology of CG Jung, 2008.

Figure 1 - Sequence of touches executed in Calatonia

The Calatonia technique was applied by the author himself, a researcher who took a specific course in the application of this technique, involving practical acquisition of skills through learning the technique and also the acquisition of a solid theoretical base.
The variables were described by their relative and absolute frequencies in each group and, when possible, measurements of central tendency and variability were also performed. 
The placebo and experimental groups were compared in relation to sex, age, pre-surgery and immediate postsurgery clinical parameters, and pain on admittance $\left(t_{0}\right)$ and after one hour at the PARR $\left(t_{1}\right)$. The pain variable was dichotomised in the analysis as follows: a score $<3$ (no pain) and a score $\geq 3$ (presence of pain). The statistical tests applied were: t-Student for the variables with normal distribution; Mann-Whitney and Chi Square, admitting a significance level of $p \leq 0.05$.

This project was approved by the Research and Ethics Committee of the study institution (protocol 05/10) and the subjects also signed an Informed Consent Form. The data was collected between March and June 2010.

\section{Results}

Out of the 116 patients in the sample, there was a predominance of female subjects $(n=72,62.1 \%)$, of which $40(68.9 \%)$ were in the placebo group and 32 $(55.2 \%)$ in the experimental group $(p=0.180)$.

In the placebo group, there was a predominance of patients between 40 and 49 years old (32.8\%), while in the experimental group there were most subjects between 50 and 60 years old (36.2\%). The mean age of the patients in the placebo group came to 42.5 years $(S D= \pm 1.4)$ while the median was 44 years (ranging from 18 up to 60 years old). In the experimental group, the mean age of the patients came to 43.3 years $(S D \pm=1.5)$ while the median was 44.5 years (ranging from 19 up to 60 years old), without there being any significant statistical differences $(p=0.689)$.
In relation to the classification according to physical state in the pre-surgery phase, we see that most subjects in the placebo group were of ASA $2(n=31$; $53.4 \%$ ) while the experimental group had the same percentage of subjects classified as ASA 1 and ASA $2(n=29 ; 50 \%)$, without any statistically significant differences $(p=0.853)$.

Regarding the type of anaesthetic, most of the people received endovenous general anaesthesia, both in the placebo group $(n=30 ; 51.8 \%)$ and in the experimental group $(n=39 ; 67.2 \%)$.

The two groups had similar mean surgical times $(p=0.936)$ when compared, with the duration of the procedure within the placebo group being 1 hour and 56 minutes ( $\mathrm{SD}= \pm 33$ minutes) and in the experimental group 1 hour and 57 minutes ( $S D= \pm 36$ minutes). The same was the case when we considered the time at the PARR ( $p=0.872)$, where the placebo group had an average permanence of 1 hour and 21 minutes $(S D= \pm 28$ minutes) and the experimental group 1 hour and 16 minutes ( $\mathrm{SD}= \pm 17$ minutes).

The clinical parameters assessed prior to the operation (namely arterial blood pressure, heartbeat, breathing rate and temperature) showed no significant statistical differences between the placebo and experimental groups $(p>0.20)$. The same was the case with post-surgery at $t_{0}$, with the exception of temperature (Table 1 ). In the case of the appraisal at $t_{1}$, after intervention, there was no observed significant statistical difference either, considering clinical parameters, between the placebo and the experimental groups.

Table 1 - A comparison of groups with regard to the mean values of clinical parameters at immediate post-surgery. São Paulo, SP, Brazil, 2010

\begin{tabular}{|c|c|c|c|c|c|}
\hline \multirow{2}{*}{$\begin{array}{c}\text { Clinical Parameters at immediate } \\
\text { post-surgery }\end{array}$} & \multicolumn{2}{|c|}{ Placebo Group (n=58) } & \multicolumn{2}{|c|}{ Experimental Group $(n=58)$} & \multirow{2}{*}{$\mathbf{p}^{*}$} \\
\hline & Mean & Standard Deviation & Mean & Standard Deviation & \\
\hline \multicolumn{6}{|l|}{ Admittance to $\operatorname{PARR}^{\dagger}\left(\mathrm{t}_{0}\right)$} \\
\hline Systolic BP $¥$ (mmHg) & 125.7 & 12.8 & 125.8 & 17.4 & 0.976 \\
\hline Diastolic BP (mmHg) $^{\prime}$ & 77.0 & 10.1 & 72.5 & 14.9 & 0.057 \\
\hline Heart Rate (beats/min) & 73.3 & 14.4 & 76.0 & 16.7 & 0.365 \\
\hline Breathing (breaths/min) & 15.5 & 2.9 & 15.2 & 3.1 & 0.984 \\
\hline $\mathrm{T}^{\circ}\left({ }^{\circ} \mathrm{C}\right)$ & 34.9 & 0.9 & 34.5 & 1.0 & 0.024 \\
\hline $\mathrm{O}_{2}$ Saturation $(\%)$ & 98.8 & 2.3 & 98.3 & 2.4 & 0.290 \\
\hline \multicolumn{6}{|l|}{ Assessment after 1 hour $\left(t_{1}\right)$} \\
\hline Systolic $\mathrm{BP}^{\ddagger}(\mathrm{mmHg})$ & 121.8 & 12.1 & 118.5 & 15.8 & 0.205 \\
\hline Diastolic $\mathrm{BP}^{\ddagger}(\mathrm{mmHg})$ & 72.5 & 9.9 & 68.7 & 12.6 & 0.069 \\
\hline Heart Rate (beats/min) & 72.9 & 13.0 & 72.8 & 13.6 & 0.967 \\
\hline Breathing (breaths/min) & 17.5 & 21.4 & 14.9 & 2.7 & 0.357 \\
\hline $\mathrm{T}^{\circ}\left({ }^{\circ} \mathrm{C}\right)$ & 35.7 & 0.6 & 35.7 & 0.7 & 0.960 \\
\hline $\mathrm{O}_{2}$ Saturation $(\%)$ & 95.9 & 2.8 & 95.5 & 2.8 & 0.462 \\
\hline
\end{tabular}

* Student's t-test; + Post-Anaesthetic Recovery Room; ₹ Blood Pressure 
In relation to the verbal numeric assessment of pain in the placebo and experimental groups, it must be remembered that, in this study, we decided to dichotomise the numeric scale for pain assessment, normally on a scale from 0 to 10 , as follows: a score of less than 3 was considered as absence of pain, while a score of 3 or over was presence of pain.

Using this scale, we could see than 44 (75.9\%) of patients in the placebo group did not show any pain, while $14(24.1 \%)$ reported presence of pain, on admission to PARR $\left(t_{0}\right)$. In the experimental group, 47 patients $(81.0 \%)$ did not report any pain straight after they received the Calatonia technique, and 11 $(19.0 \%)$ patients mentioned pain on admittance to the PARR $\left(T_{0}\right)$.

After 60 minutes at the PARR $\left(T_{1}\right)$, it was observed that 49 patients, or $84.5 \%$ of the universe considered in the placebo group, reported absence of pain, while $9(15.5 \%)$ showed pain. In the experimental group, no pain was reported in the cases of 57 patients (98.3\%) with only one patient $(1.7 \%)$ reporting pain. At this moment, there is a statistically significant difference between them $(p=0.016)$.

From these results, we can conclude that a larger group of patients in the experimental group did not show presence of pain (score $<3$ ), as mentioned in the patient's post-anaesthesia recovery (Table 2 ). It must also be mentioned that this experimental group stayed less time at the PARR as, without any pain and showing stability of clinical parameters, they were able to obtain conditions allowing them to be discharged from the PARR.

Table 2 - Distribution of surgery patients, of placebo and experimental groups, according to the numeric appraisal of pain at Post-Anaesthetic Recovery Room (PARR). São Paulo, SP, Brazil, 2010

\begin{tabular}{|c|c|c|c|c|c|}
\hline \multirow{2}{*}{ Pain } & \multicolumn{2}{|c|}{$\begin{array}{c}\text { Placebo } \\
\text { Group }(n=58)\end{array}$} & \multicolumn{2}{|c|}{$\begin{array}{l}\text { Experimental } \\
\text { Group }(n=58)\end{array}$} & \multirow{2}{*}{$\mathbf{p}^{*}$} \\
\hline & $\mathbf{n}$ & $\%$ & $\mathbf{n}$ & $\%$ & \\
\hline $\begin{array}{l}\text { Admittance to } \\
\operatorname{PARR}^{\dagger}\left(\mathrm{t}_{0}\right)\end{array}$ & & & & & 0.652 \\
\hline No $(<3)$ & 44 & 75.9 & 47 & 88.1 & \\
\hline Yes $(\geq 3)$ & 14 & 24.1 & 11 & 19.0 & \\
\hline Total & 58 & 100.0 & 58 & 100.0 & \\
\hline $\begin{array}{l}\text { Appraisal after } \\
1 \text { hour }\left(t_{1}\right)\end{array}$ & & & & & 0.016 \\
\hline No $(<3)$ & 49 & 84.5 & 57 & 98.3 & \\
\hline Yes $(\geq 3)$ & 9 & 15.5 & 1 & 1.7 & \\
\hline Total & 58 & 100.0 & 58 & 100.0 & \\
\hline
\end{tabular}

* Fisher's Exact Test

+ Post-Anaesthetic Recovery Room

\section{Discussion}

It is important to mention that there are few studies about the use of complementary therapies in the immediate post-operatory period. It is believed that this scarcity is a consequence not only of the lack of inclusion of AT/CT in graduation courses and of the biomedical model, but also of the difficulty to measure the effects produced by AT/CT using traditional methodologies.

This full knowledge about the individual, abandoned with the development of more sophisticated drugs and powerful pharmaceutical products, is now being recovered through the nursing professionals, who see it as an important resource for interaction with the patient, both in the creation of bonds of empathy, as also in the aid to stabilisation of the emotional and physical balance(18).

In this study, we have seen that most of the patients were female, and the most common age bracket was 40 to 49 years old, data which matches that of other studies conducted on patients submitted to cholecystectomy by laparoscopy(19-20). Gallstones are one of the most common ailments afflicting the digestive tract, affecting $20 \%$ of the adult population and mostly women ${ }^{(21-22)}$. This has been put down to successive pregnancies, use of the contraceptive pill, or therapeutical hormone substitution, as oestrogen, which is the female hormone used in hormone replacement therapy, could be responsible for inflammatory processes and symptoms which simulate those of gallstones.

In terms of surgical risk, most have been ASA 2 with the base pathology being either high blood pressure or compensated diabetes. It is worth stressing the fact that, for the analysis of the clinical parameters of the pre-operatory period, these patients treated with the aid of beta blockers and drugs to reduce blood sugar. It is also important to mention that, for the analysis of the clinical parameters in the post-surgery period, the patients treated with beta blockers and drugs to reduce blood sugar have not been separated into different subgroups. The stability of the clinical parameters as presented, both by ASA 1 and ASA 2 patients, has brought conditions favourable to discharge from the PARR.

In terms of the type of anaesthesia used for the exploitation of the biliary ducts by videolaparoscopy, endovenous general anaesthesia stood out. The choice of the type of anaesthesia to be applied depends on the physiological conditions of the patient and also other particularities, with the final choice of anaesthetic 
procedure being at the discretion of the anaesthetist, by consensus with the doctor ${ }^{(23)}$.

Some AT/CT have been used together with the technique of anaesthesia seeking to reduce the consumption of opiates in the intrasurgical period. As an example, we have acupuncture which has been used in the perisurgical period, not to produce real anaesthesia or unconsciousness, but rather to reduce the consumption of volatile or opiate anaesthetics, as this prevents the activation of the pain routes ${ }^{(23)}$.

Regarding the duration of the stay at the PARR, we see a small difference between the mean stays at the PARR, of the different groups. In relation to the assessment of clinical parameters in the pre-surgery phase, on admittance to PARR $\left(t_{0}\right)$ and also on discharge $\left(t_{1}\right)$, the groups have stayed homogeneous, without any statistically significant differences. This result is put down to the bond that has been created by the researcher, towards the patient and his or her carer, providing security and peace of mind. In addition, patients with hypertension were stabilised through the use of medicines.

Even though the differences between the means of the different clinical parameters were not significant, there was a decline in the heartbeat and also a reorganisation of breathing, less significant for the experimental group. It is suggested that these differences may have occurred through the relaxation that Calatonia has provided.

Only the axillary body temperature showed a statistically significant result at the moment of admittance to PARR, when compared to the placebo group. Considering temperature as one of the vital signs as appraised and also that the organism depends on the rise thereof to increase metabolism, it has been inferred that, at this moment, the reduction in temperature was not beneficial. Even though this is highly unlikely, this reduction in temperature could be associated with the vasoconstrictive action of anaesthetic agents as yet not metabolised.

Multimodal anaesthesia and also post-surgical analgesia, performed on the patients of this study, could minimise neuroendocrine and metabolic changes arising from the surgical anaesthetic trauma, in the post-surgery period, and also pain. However, there are other aggravating circumstances in the case of complaints of pain in the post-surgery period, for this type of surgery as performed, such as irritation to the diaphragmatic peritoneum, caused by $\mathrm{CO}_{2}$ and also the strain of muscular fibres of the diaphragm, caused by the pneumoperitoneum ${ }^{(24)}$.
In the treatment of patients with pain, on top of the use of antidepressive drugs, anticonvulsives and opiates, other non-pharmacological measures such as physiotherapy, occupational therapy, AT/CT (relaxation, meditation, hypnosis, massage, chiropraxy, and transcutaneous electronic nerve stimulation) and also physical exercise all seem to be minor players here ${ }^{(25)}$.

In this study, after 60 minutes in SPRA, with the application of Calatonia on the experimental group, a statistically different result was observed, although it cannot be ruled out that the patients may have received, in the intraoperational phase, important pain-killing schemes. We also mention that, even with the analgesia received in the interoperational phase, some patients in both groups have continued to complain of pain, on being admitted to the PARR.

Even though only the experimental group has had the therapeutical touches of Calatonia, the placebo group also had an unintentional touch, meaning that all patients received individualised assistance right from the start of the research study.

\section{Conclusion}

Only axillary body temperature showed a statistically significant difference between the placebo and the experimental groups, at the moment of admittance to PARR. In relation to pain, the experimental group showed significant results, from which one can infer that the relaxation provided by the Calatonia technique brought relief of the pain observed. This means that the application of Calatonia could be a complementary resource for assistance in the immediate post-surgery period, and as such shall be shared and therefore contribute with future studies in the area of Postanaesthetic Recovery.

\section{References}

1. Bello CN. Recuperação pós-anestésica - escalas de avaliação, princípios gerais. Rev Centro Est Anest FMUSP. $2000 ; 9: 4-5$.

2. Carvalho R, Bianchi ERF. Enfermagem em centro cirúrgico e recuperação. $1^{\text {a }}$ ed. Barueri: Manole; 2007.

3. Sociedade Brasileira de Enfermeiros de Centro Cirúrgico, Recuperação Pós-Anestésica e Centro de Material e Esterilização (SOBECC). Práticas recomendadas SOBECC. $5^{a}$ ed. São Paulo: SOBECC; 2009.

4. Souza VT. Enfermeiros que trabalham com terapias complementares: conhecendo sua prática [dissertação]. São Paulo: Escola Paulista de Medicina da UNIFESP; 2000. 
5. McCloskey JC, Bulechek GM. Nursing intervention classification (NIC). 2. ed. St. Louis: Mosby; 1996.

6. Herdman TH. Nursing Diagnoses Definitions and Classification - Nanda Internacional (NANDA-I). WileyBlackwell; 2012-2014.

7. Sándor P. Técnicas de relaxamento. $4^{a}$ ed. São Paulo: Vetor; 1982.

8. Nosow V, Peniche ACG. Paciente cirúrgico ambulatorial: calatonia e ansiedade. Acta Paul Enferm. 2007;20(2):161-7.

9. Peniche ACG, Chaves EC. Surgical patient and anxiety: some consideration. Rev. Latino-Am. Enfermagem. 2000;8(1):45-50.

10. Salles LF, Ferreira MZJ, Silva MJP, Turrini RNT. Terapias complementares na enfermagem: levantamento bibliográfico. Nursing (São Paulo). 2007;9(105):94-8.

11. Tovey P, Easthope G, Adams J. The mainstreaming of complementary and alternative medicine: studies in social context. London: Routledge; 2003.

12. Adams J, Tovey P. Complementary and alternative medicine in nursing and midwifery: critical readings. London: Routledge; 2006.

13. Souza EFA, Luz MT. Bases socioculturais das práticas terapêuticas alternativas. Hist Ciênc Saúde-Manguinhos. 2009;16(2):393-405.

14. Conselho Regional de Enfermagem de São Paulo (COREN). Documentos básicos de enfermagem: principais leis e resoluções que regulamentam o exercício profissional de enfermeiros, técnicos e auxiliares de enfermagem. São Paulo: Escrituras; 2008.

15. Conselho Federal de Enfermagem (COFEN) (BR). Resolução n. 197, de 19 de março de 1997. Estabelece e reconhece as terapias alternativas como especialidade e/ ou qualificação do profissional de enfermagem [Internet]. Brasília; 1997. [acesso 12 jan 2011]. Disponível em: http://site.portalcofen.gov.br/node/4253.

16. Farah RM. O trabalho corporal e a psicologia de C.G. Jung. $2^{a}$ ed. São Paulo: Companhia Ilimitada; 2008.

17. 15. Rosner B. Fundamentals of Biostatistics. $6^{a}$ ed. Belmont: Thompson Brooks/Cole; 2006. 416 p.

18. Gala MF, Telles SCR, Silva MJP. Ocorrência e significado do toque entre profissionais de enfermagem e pacientes de uma UTI e unidade semi-intensiva cirúrgica. Rev Esc Enferm USP. 2003; 37(1):52-61.

19. Henriques AC, Pezzolo S, Gomes M. Colecistectomia videolaparoscópica ambulatorial- estudo de 60 casos. Arq Med ABC. 2002;27(2):6-8.
20. Dalri CC, Rossi LA, Dalri MCB. Nursing diagnoses of patients in immediate postoperative period of laparoscopic cholecystectomy. Rev. Latino-Am. Enfermagem. 2006;14(3):389-96.

21. Fiorillo MA, Davidson PG, Fiorillo M, D'Anna JA Jr, Sithian N, Silich RJ. 149 ambulatory laparoscopic cholecystectomies. Surg Endosc. 1996;10(1):52-6.

22. Haicken BN. Laser laparoscopic cholecystectomy in the ambulatory setting. J Post Anesth Nurs. $1991 ; 6(1): 33-9$.

23. Ortenzi AV. Avaliação e medicação pré-anestésicas. In: Yamashita AM, Takaoka F, Auler JOC Jr, Iwata MN, editores. Anestesiologia - Sociedade de Anestesiologia do Estado de São Paulo (SAESP). $5^{a}$ ed. São Paulo: Atheneu; 2001. p. 467-97.

24. Cunningham AJ, Brull S. Laparoscopic cholecystectomy: anesthetic implications. Anesth Analg. 1993;76(5):1120-33.

25. Sampaio LR, Moura CV, Resende MA. Recursos fisioterapêuticos no controle da dor oncológica: revisão da literatura. Rev Bras Cancerol. 2005;51(4):339-46. 